\title{
Advice from Creative Consumers: A Study of Online Hotel Reviews
}

\author{
Abstract \\ This study explores what creative consumers are compelled to say about hotels through online \\ reviews. Online reviews are highly influential, with consumers preferring the advice of other \\ consumers over industry experts or information provided by the marketer. Over 7,000 online \\ hotel reviews posted on TripAdvisor were examined, using Leximancer, a content analysis tool. \\ This study provides insights on the factors contributing to guest satisfaction and dissatisfaction in \\ luxury hotels and moderate hotels. It also demonstrates the importance of the information \\ provided by creative consumers, both in terms of market research and as part of an overall \\ marketing communications initiative.
}

Keywords: online hotel reviews, content analysis, TripAdvisor, Leximancer, hotel chains, eword-of-mouth, consumer-generated content, user-generated content, creative consumers 


\subsection{Introduction}

Consumers today have unprecedented power. Through social media, "individuals and communities share, co-create, discuss, and modify user-generated content" (Kietzmann et al., 2011). Consequently, not only can consumers easily disseminate their views on a purchase through ratings, reviews, and online feedback, but other consumers are interested in knowing these views. In fact, recommendations from other consumers have more influence on a purchase than reviews from experts or information provided by the marketer (Sparks and Browning, 2011). This sort of communication and feedback is especially valuable to companies operating in industries with challenging velocity regimes, i.e. the industry is experiencing diverse and potentially contradictory rates and directions of change (McCarthy et al., 2010).

This study explores the advice creative consumers contribute through online hotel reviews. These consumers are creating their own reviews and providing others with valuable recommendations about accommodation. A creative consumer was defined by Berthon et al. (2007) as any "individual or group who adapts, modifies, or transforms a proprietary offering, such as a product or service". This study expands the definition of creative consumers to include those who create user-generated content, consistent with the Organisation for Economic Cooperation and Development that defines user-generated content as "content made publicly available over the Internet, which reflects a certain amount of creative effort, and which is created outside of professional routines and practices" (May, 2012). In the case of online hotel reviews, creative consumers are adapting the previously understood notion of hotel reviews, liberating them from the purview of professional travel writers and reviewers and reinventing them as the realm of consumer journalism and user-generated content. 
This study examines online hotel reviews on TripAdvisor, a website that presents reviews and advice on hotels and other aspects of travel. The technology of TripAdvisor is facilitating creative consumers' ability to create their own hotel reviews and hotel star ratings, consistent with the enable stance, one of four stances described by Berthon et al. (2007). While hotel star rating systems are well known, they were traditionally conferred by professional bodies such as hotel associations, tourism organizations, and the American Automobile Association (with its diamond ratings). The hotels on TripAdvisor receive their star ratings not from professional bodies but from creative consumers. In this sense, the proprietary offering of hotel ratings and reviews has been co-opted and transformed by creative consumers. While conferred hotel star ratings were prescriptive and conformed to particular standards, star ratings given by consumers are based on what is important for a majority of the consumers who contribute star ratings. Furthermore, while hotel reviews tend to follow the norms set by an organization or by a publication, hotel reviews by consumers follow no set template and can be as idiosyncratic as any individual. The concept of consumers writing reviews was also described by Kozinets et al. (2008) in their research on innovation-oriented online consumer communities. This study uses the terms consumer-generated content and user-generated content synonymously.

Using the contributions by creative consumers, this study builds on previous research and provides greater depth and context to what is important to hotel guests. This study examines over 7,000 online hotel reviews posted on TripAdvisor using Leximancer, a content analysis tool. Literature on the influence of consumer-generated online reviews is presented, followed by a description of the study methodology. The study results are discussed, along with Leximancer concept maps, followed by conclusions and implications, and, finally limitations and areas for future research. 


\subsection{Background and Literature Review}

Online reviews are a form of electronic word-of-mouth (eWOM). The motivation for consumers to provide eWOM includes social benefits, concern for others, extraversion/selfenhancement, as well as economic benefits (Hennig-Thurau et al., 2004; (Dolnicar, 2002). eWOM enables a participatory culture that allows ordinary citizens to express themselves and disseminate their creativity (Daugherty, Eastin, \& Bright, 2008). Research on eWOM in the travel sector has been primarily focused on online hotel reviews and has found that consumergenerated online reviews were the most influential for decisions on accommodation, over other travel decisions (Gretzel and Yoo, 2008). Eighty-four percent of potential hotel visitors who consult online review sites were affected by these reviews (Vermeulen and Seegers, 2009).

Consumers read online reviews to reduce purchase uncertainty in general (Mudambi and Schuff, 2010). With travel, consumers are making decisions involving fairly large amounts of money, where the wrong decision could have a significant negative impact on personal finances as well as precious vacation time. Hundreds of millions of potential hotel visitors consult online review sites (Vermeulen and Seegers, 2009). Creative consumers who write the online hotel reviews are mostly motivated by a concern for other potential visitors, helping a hotel, and the need for extraversion and positive self-enhancement. Receiving rewards for postings is not an important motivation for those writing online hotel reviews, nor is venting negative feelings (Gretzel and Yoo, 2008). Consumer creativity is enhanced when consumers are creating because of intrinsic motivation or out of sheer interest (Burroughs and Mick, 2004)which is a major reason for consumers writing reviews about hotels. 
With online reviews, consumers have the opportunity to control information about products and services, and can frame "these descriptions within their own personal experiences versus that of a marketer." Other consumers value the work of these creative consumers, as the recommendations of other consumers have been found to influence product choice more than reviews from experts (Sparks and Browning, 2011). While consumer-generated reviews are considered more reliable and more likely to provide up-to-date information, fellow consumers also recognize they may not provide the detailed information that may be most relevant to them (Gretzel and Yoo, 2008).

There are differing points of view on the importance of positive and negative consumergenerated reviews. Miao et al. (2011) argue that negative eWOM is more powerful than positive eWOM in influencing hotel bookings. Mudambi and Schiff (2010) suggest that moderate reviews are more helpful than extremely positive or extremely negative ones. Sparks and Browning (2011) and Vermeulen and Seegers (2009) suggest that positive hotel reviews have a larger impact on consumer behaviour than negative reviews. Whitehead (2011) conducted an extensive literature review, and identified research gaps and propositions for future research for online reviews and TripAdvisor.

The effect of consumer-generated hotel reviews differs depending on the hotel. They may be more influential for lesser known hotels that do not have the benefit of a known brand image. Exposure to positive reviews reduces price sensitivity (Vermeulen and Seegers, 2009), likely pertaining more to luxury hotels than moderate or budget hotels.

Hotel guests expect a higher level of service when they pay more, as would be expected. But when price is removed as a factor, the most influential factors in selecting a hotel were convenient location followed by good service provided by hotel staff (Chan and Wong, 2006). 
In a previous study on online hotel reviews in Portugal, the subjects that came up most frequently included room, staff, location, hotels, and breakfast; the most important categories were room and staff. The most frequent qualifiers to these categories were "cleanliness, friendliness, helpfulness, centrality, size, silence, diversity, price, proximity to public transport, design, bed, and Internet" (Chaves et al., 2011). Choi and Chu (2001) indicate staff service quality was the most important factor in overall satisfaction, followed by room qualities, value, general amenities, international direct dial facilities, business services, and security. Dolnicar (2002) shows that the top five expectations of business travellers were, in order: cleanliness, friendliness, good food, a television set in the room, and service. The top disappointments of these business travellers were, in order, lack of cleanliness, room design and setup, personnel, service, and unfriendly staff. This study builds upon these insights, providing additional depth and context that draws upon a content analysis of over 7,000 online reviews.

Online reviews are important to prospective consumers and they should be important to hotel management. A study by Expedia showed that a one point increase in a review score equates to a $9 \%$ increase in average daily rate (May, 2012). However, while $90 \%$ of hotel managers thought online reviews were very important, only $15 \%$ had policies or guidelines for what to do about them (Barsky and Nash, n.d.). Litvin et al. (2008) suggested eWOM can be used to make management decisions about product improvement and solving visitor problems among others.

Consumer-generated online hotel reviews are widely consulted by other consumers. They are important to hotel managers yet the information contained in them may not be fully utilized. This study used qualitative methods to examine online hotel reviews on TripAdvisor to better understand the insights that can be gleaned from them. The research questions were: 
- What is important for creative consumers at leading hotel chains? What is important among those staying at luxury hotel chains versus those staying at moderate hotel chains?

- What are the commonalities and differences in the reviews among the most satisfied creative consumers and least satisfied creative consumers?

\subsection{Methodology}

TripAdvisor was chosen was the source for the consumer-generated online hotel reviews because it is the world's top online hotel review site, with over 75 million reviews and more than 60 million unique monthly visitors (May, 2012; (Keen, 2008). The hotels included in this study were chosen from two lists:

- Top 10 Luxury Hotel Chains, compiled from lists from Conde Nast and Travel + Leisure (Morelock, n.d.)

- Top 10 Hotel Chain Brands by Heardable (Samsel, 2012). This list is based on online performance and scores the brand health of hotel chains out of 1,000 possible points.

From these two lists, a total of 17 hotel chains were studied. Two hotel chains from the list of Top 10 Luxury Hotel Chains were not included because they were small chains or were limited geographically compared to the other hotel chains.

From each hotel chain, three hotels were selected for the study. The three hotels were located in three different countries, preferably on different continents for breadth reasons. Where possible, hotels in major cities such as New York, London, and Hong Kong were selected. The choice of three hotels from each hotel chain was made so the combined reviews were more indicative of the hotel chain as a whole. Each hotel chain was categorized as luxury or moderate based on the ratings for the specific hotels studied. For this study, a luxury hotel 
chain is one that received more five-star ratings on TripAdvisor than any other category while a moderate hotel chain received more four- or three-star ratings. On TripAdvisor, the star ratings are based on the scores given by reviewers and show an overall average as well as the number of reviews for each star rating. Of the 17 hotel chains, 12 were categorized as luxury and 5 as moderate. See Appendix 1 for the list of hotels and their categorization.

For each hotel, one year of reviews was included in the study (October 2011 to September 2012, inclusive). In total, this study included 7,439 online hotel reviews, grouped as follows:

- Group 1: luxury chains receiving 5 star reviews (3,563 reviews)

- Group 2: luxury chains receiving 3 star and below reviews (522 reviews)

- Group 3: moderate chains receiving 4 and 5 star reviews (2,860 reviews)

- Group 4: moderate chains receiving 2 star and below reviews (494 reviews).

For the luxury hotel chains, this study considers the reviews that gave a rating of 5 stars as positive reviews while considering the reviews that gave a rating of 3 stars and below as negative reviews. The 4 star reviews were not selected in order to better separate the positive aspects from the negative. Likewise, for the moderate hotel chains, the 4 and 5 star reviews represented the positive reviews while the 2 star and below reviews represented the negative reviews, and the 3 star reviews were not selected.

TripAdvisor's primary function is to collect and disseminate user-generated content related to travel and its most prominent features are its consumer-generated reviews and ratings. The content contributed by consumers is examined by TripAdvisor to ensure it meets content guidelines and, once approved, the content is added and displayed indefinitely. While hotels have the opportunity to respond to each review, requests from hotels to remove or edit reviews are not entertained (RW.ERROR - Unable to find reference:101). There has been some concern 
about fake reviews but O'Connor (2008), in a study of TripAdvisor reviews, believed only about $1 \%$ could be considered fake reviews and that as the number of reviews grows, the impact of fake reviews falls.

This study used Leximancer to conduct a content analysis among the four groupings of online hotel reviews. Leximancer is a content analysis tool that allows researchers to analyze large amounts of text in a way that removes researcher bias (Penn-Edwards, 2010). It allows researchers to visualize and interpret complex text using an algorithm based on Bayesian theory and has been used to analyze consumer-generated content and conversations (Campbell et al., 2011). It uses word frequency and co-occurrence counts and the analysis used these to produce a concept co-occurrence matrix (Rooney, 2005). Leximancer has been used in tourism to analyze tourism destination websites (Kattiyapornpong and Nel, 2012; Pitt et al., 2008) and consumergenerated content (Campbell et al., 2011).

Leximancer concept maps were used to identify the important themes and concepts among the four groupings of hotel reviews. Based on the Leximancer-identified important themes and concepts, the text associated with the important themes and concepts was reviewed manually to identify the specific context in which the themes and concepts appeared.

In Leximancer, concepts are collections of words that appear together through the text. They appear on the concept map clustered together into themes and the proximity of different concepts and themes on the concept map is related to their co-occurrence in the same pieces of text. This means that the closer the concepts/themes appear on the Leximancer map, the more often they co-occur in the text examined. Leximancer quantifies the relationships between concepts and uses their co-occurrence to draw the concepts maps. The themes are shown on the concept map as coloured circles and are heat-mapped to show importance, with the hottest or most important 
themes in red and the next most important according to the colours on the colour wheel. The concepts are shown as dots with lines connecting different concepts (Leximancer, 2011).

This study used the default settings but did select word merge that employs a stemming algorithm to identify the headword (Leximancer, 2011). With the word merge turned on, words such as room/rooms and love/lovely were grouped together.

\subsection{Results}

The study results identify the most important themes for each of the four groups of consumer-generated hotel reviews based on the colours of themes on the Leximancer concepts maps, then identify the common and unique themes among the luxury hotels and among the moderate hotels. Within the themes, the concepts that make up each theme and how the various concepts and themes relate to each other are examined.

\subsection{Most Important Themes}

These creative consumers were independent of the hotels and of TripAdvisor and they were free to write about whatever was important to them in their creative piece: the online review. Each review can be as idiosyncratic as each individual consumer. Because of this independence and ability to be idiosyncratic, the value of the advice from creative consumers is in their collective commonality. This study examines the most important common themes among each of the four groupings of hotels in this section. The most important themes are identified by colour, starting with red and moving through the colour wheel. For this study, the most important themes were those coloured red, yellow, and yellowish green. 


\subsubsection{Group 1: Luxury Hotel Chains - Positive Reviews}

For the creative consumers who wrote positive reviews about the luxury hotel chains, the most important themes were room and hotel, followed by staff and service. See Figure 1 for the concept map. The themes and comments in the positive reviews should be likened to advice about the aspects of a luxury hotel experience that were important to creative consumers.

In the room theme, consumers commented about the largeness of the room, tasteful décor, luxuriousness, cleanliness (with words such as "spotless" and "immaculate"), an upgraded room, or solving of a room problem.

The hotel theme appeared to be where consumers summed up their experience of the hotel, with comments about the particular hotel being "my hotel of choice", favourite hotel in the destination, "five star hotel", and "best hotel experience". The hotel theme also included descriptions of the hotel, including recent renovations, and included comments about the hotel being expensive but worth it. The hotel theme was not located close to the room theme, indicating these two themes did not have as many co-occurrences as others. However, the hotel theme overlapped with the service theme, suggesting a close association between exemplary service and the overall experience of the hotel.

Staff and service are closely connected, as these two themes appear on the concept map beside each other. Consumers make general comments in the service theme, with comments such as "outstanding service", "highest levels of service", "enjoyed the service", and "thoughtful service". However, in the staff theme, the personalities of staff or individual staff are noticed, with comments such as "staff are adorable", "welcoming staff", "staff were gracious and pleasant", and "my problems were solved by staff".

\section{INSERT FIGURE 1 ABOUT HERE}




\subsubsection{Group 2: Luxury Hotel Chains - Negative Reviews}

Advice from creative consumers about opportunities to improve the hotel experience was in the negative reviews. For the luxury hotel chains, the most important themes were room and hotel, followed by told, time, and service. See Figure 2 for the concept map.

In the room theme, the areas for improvement were small rooms, aspects of room ambiance such as temperature and technology, cleanliness, and rooms being dated and noisy. In the hotel theme, consumers expressed their disappointment with the particular hotel compared to other luxury hotels, with comments that details are important for a hotel of this calibre. The hotel theme was not located close to the room theme, indicating these two concepts are not directly related.

In the told theme, consumers said they were told about policies and rules when something they expected did not occur, they were told their room was not ready, or there were extra fees. Many of the comments around the told theme occurred at the front desk or at a hotel restaurant. In the time theme, consumers mentioned needing to wait too long for an item or service, asking several times for an item or service, or despite trying several times, the key would not work.

The service theme consisted primarily of service disappointments such as "service not so good", inconsistent service, and "disappointed by the service". There were some comments such as "poor service", "worst service", "terrible service", and "service was a letdown". In a few instances, there were comments about "good service" or "good service but..." a letdown in another area of the hotel experience. The service theme included comments about the restaurants and room service. The service theme is closer to the hotel theme than the room theme to the hotel theme, meaning that the concepts in the service theme co-occur with the concepts in the 
room theme more often than their co-occurrences with the concepts in the hotel theme. This suggests the service levels that guests of luxury hotels receive affect their view of the hotel more than the room itself.

\section{INSERT FIGURE 2 ABOUT HERE}

\subsubsection{Group 3: Moderate Hotel Chains - Positive Reviews}

For creative consumers who stayed at moderate hotel chains and wrote positive reviews, the most important themes were room, followed by hotel, staff, and location. See Figure 3 for the concept map.

In the room theme, creative consumers commented about the smallness of the room. Other aspects of the room that needed improvement were room amenities, hanging space, lighting, safe in the room, temperature of the room, and comfortable bed and furniture. The cleanliness of the room was noticed, with positive mentions in these positive reviews, interspersed with some negative comments as well. Even in the positive reviews, a few creative consumers would have liked a refrigerator or safe in the room, and Internet.

In the hotel theme, comments included "good value hotel", "good hotel", and "old classic hotel", "nice place". They appreciated nearby public transportation, writing that the "hotel is central", "close to everything", and "well placed".

The staff theme included mostly positive comments about the staff, such as "impressive staff", "all staff are exceptional and go the extra mile", "professional", "patient", "courteous", “polite”, “accommodating”, "friendly", "helpful”, and "good attitude”. There were positive comments about specific staff such as housekeeping staff, executive staff, and restaurant staff, and specific mention of staff solving problems. A few negative comments about staff were 
made, including "cold reception staff", staff did not smile, and they talked to each other when they should have been helping guests. While creative consumers of the luxury hotels separated out service levels from staff attributes, the creative consumers of the moderate hotels focused more on staff attributes.

Consumers in the location theme liked central locations: "great location", close to shopping, walking distance to tourist sites, and being the perfect location for the guest. There were a few comments about traffic noise due to the location.

Like the luxury hotel chain reviews, the staff theme is closer than the room theme to the hotel theme on the concept map, and means the staff theme is more closely connected to the hotel theme. This suggests a close association between positive views of the staff and positive views of the hotel.

\section{INSERT FIGURE 3 ABOUT HERE}

\subsubsection{Group 4: Moderate Hotel Chains - Negative Reviews}

How moderate hotel chains could improve their offerings were detailed in the negative reviews (those giving 2 star ratings or lower) and the most important themes were hotel and room, followed by front, day, and staff, in order of importance. See Figure 4 for the concept map.

The hotel theme included strong statements primarily about staying away from this hotel, with suggestions about "hotel needs love and attention", "hotel gone downhill", and "feels dated". Among these negative statements, there were comments that the only positive thing about this hotel was the location. 
Advice in the room theme included better maintenance of the rooms, better cleaning of the rooms, and improved beds. Room maintenance improvements suggested by consumers included "rooms need renovation", "small and dingy room", and "room was freezing". Comments about cleanliness centred around "peeling wallpaper with mold", "smelled like smoke", "mold growing”, “dirty stinky room", “mildew smell”, “smelled like urine”, or "smelled like air freshener”. Beds could be more comfortable, larger, and some had bed bugs.

In the front theme, consumers complained that the front desk staff were "rude", "cold", failed to solve problems, not welcoming, did not answer the phone, "unfriendly", and "staff was irritated by requests". There were a few comments about small or inadequate desks in the rooms. In the day theme, consumers did not like the additional fees per day (parking, breakfast, Internet).

In the staff theme, consumers had mostly negative comments about the staff in general and about specific staff such as "porter staff abrupt", "staff need seminar on friendliness", "staff disinterested", "staff cold", "staff manner was off hand", and "staff was mocking him". They noted some positive aspects about the staff such as "staff was courteous", "efficient", "some staff were good, others were not", and "some friendly and helpful".

The staff theme and hotel theme overlap slightly on the concept map, indicating a high degree of co-occurrences between these two themes and their respective concepts. This suggests that the experience of creative consumers with staff had a significant effect on their overall assessment of the hotel. The room theme is further from the hotel theme, indicating that staff is more important than the room in the overall impression of the hotel for these negative reviews and for all four groups of reviews.

INSERT FIGURE 4 ABOUT HERE 


\subsection{Common and Unique Themes}

From the content analysis, it was possible to identify themes that were common among the positive and negative reviews or unique to the positive reviews or unique to the negative reviews.

\subsubsection{Luxury Hotel Chains}

For the luxury hotel chains, the common themes among the positive and negative reviews included room, hotel, service, breakfast, and nice. See Table 1 for the lists of the common and unique themes. The first three listed under common themes were among the most important themes for the luxury hotels, for both the positive and negative reviews. The themes of breakfast and nice are less important but in luxury hotels where a guest has high expectations, they can likely make the difference between a consumer feeling truly pampered versus just staying in a high quality hotel.

There were negative comments about breakfast in the positive reviews and positive comments about breakfast in the negative reviews, suggesting that an average breakfast is not enough to significantly affect a creative consumer's positive review of a hotel nor is a good breakfast enough to change a negative review of a hotel.

The nice theme among the positive reviews was primarily about little extras, "nice touches" such as a welcome package with wine and snacks, cookies, designer bath products, and hotel car.

\section{INSERT TABLE 1 ABOUT HERE}


In the luxury hotel chains, the positive reviews included unique themes of staff, location, lovely, stayed, recommend, (front) desk, worth, and shower. An aspect of particular interest was the shower theme that referred to positive experiences with rain shower heads, good water pressure, and hot water, with suggestions about wanting a separate shower from the bathtub, shower being too small, and wanting better quality bath products.

For creative consumers writing negative reviews, the unique themes included time, told, better, business, bathroom, food, table, door, old, and Savoy. In particular, the bathroom theme had complaints about the bathrooms being old, dirty, not well maintained, small, and "smelly". The old theme included comments about the building being old, old towels, old carpets, and old furniture.

\subsubsection{Moderate Hotel Chains}

For the moderate hotel chains, the common themes among the positive and negative reviews included room, hotel, staff, location, and day. See Table 2 for the lists of the common and unique themes. The first three themes have been discussed in section 4.1.3. The location theme included comments that the hotel may be in a good location but provided "nothing else", one was just "paying for location", and the hotel did not provide "good value" despite the location.

\section{INSERT TABLE 2 ABOUT HERE}

In the positive reviews, the unique themes included executive, stay, airport, breakfast, and London. The breakfast theme had numerous comments about breakfast being expensive, whether breakfast was included or not, and the quality of the breakfast. 
In the negative reviews, the unique themes included front (desk), night, bathroom, morning, hot, tea, food, money, and Hilton. The bathroom theme primarily included complaints about the condition of the bathroom and poor amenities.

\subsection{Discussion}

This study examined what is important for creative consumers at leading hotel chains and the commonalities and the differences in what was mentioned among the most satisfied and least satisfied creative consumers. This study examined online hotel reviews and did not attempt to include a representative sample of hotel guests. Positive and negative reviews were studied and did not include moderate reviews: for the luxury hotels, only the reviews of those consumers giving 5 star ratings and those giving 3 star ratings or below were studied, and did not include the reviews associated with the moderate 4 star ratings. For the moderate hotels, only the reviews of those consumers giving 4 star ratings and above and those giving 2 star ratings and below were examined, and did not include the reviews associated with the moderate 3 star ratings. Through the examination of the more positive or negative reviews, this study sheds more light on opportunities and advice given by creative consumers.

Individual online hotel reviews can be quite idiosyncratic, as creative consumers are free to provide kudos, complaints, and ideas for improvement whether they suit other guests or whether they suit their particular circumstances only. However, when examined together, the common elements can be identified. While the study does confirm the most important factors in a satisfactory hotel stay and is consistent with previous studies, it provides greater context and detail through the examination of over 7,000 online hotel reviews. As a result, it contributes 
greater knowledge about the factors contributing to guest satisfaction and dissatisfaction in luxury hotels and moderate hotels.

This paper demonstrates the importance of the information provided by creative consumers, both in terms of using this information as a form of market research and in terms of managing this content as part of an overall marketing communications initiative. This study on online hotel reviews on TripAdvisor has demonstrated that, examined as a group, the often idiosyncratic contributions of individual creative consumers are consistent with findings from quantitative studies and thus can be used as legitimate advice to management. However, because the online hotel reviews do not necessarily follow a particular format and can cover any topic that is of interest to the particular consumer, they provide greater depth and reasoning than quantitative studies. The implications for hotel management and for creative consumers are discussed below.

\section{$\underline{5.1 \text { Implications for Hotel Management Research }}$}

This study builds on previous research about what is important in a hotel stay (Chan and Wong, 2006; Chaves et al., 2011; Choi and Chu, 2001). The major findings in this study are consistent with those identified in previous studies but presents richer and deeper context, using advice freely provided by creative consumers. Previous studies on the importance of different hotel attributes have, for the most part, used surveys and relied primarily on quantitative information (Hirschman, 1980). Due to the richness of detail that is available through creative consumers writing their own reviews, this study provides more specifics about what constitutes a satisfactory or unsatisfactory stay. This study confirms the top factors of service or staff and room and provides additional specifics about particular aspects of these factors that contribute to 
satisfaction and dissatisfaction. This study provides a richness of detail that was not available previously.

For luxury hotels, creative consumers identify the most important aspects to their hotel experience as the guest rooms, service levels, and staff; this is consistent with previous literature. However, creative consumers further specify that guest rooms should be large, tastefully and luxuriously appointed, well maintained, quiet, and spotlessly clean. Service levels (i.e. having enough staff) need to be high enough that guests feel they are important and catered to without having to wait for service. The people hired as staff, whether on the front desk, in room service, housekeeping, restaurant, pool, or any place where guests could come into contact with them, should be genuinely welcoming, gracious, and friendly. Staff should have the authority to solve problems rather than citing rules and policies. Location was a less important theme in the study, likely because the location was known prior to the stay. Both positive and negative reviews for the luxury hotels noted the central locations but having a good location is not enough to prompt positive reviews.

In luxury hotels, the little extras (such as delicious, generous breakfast with lots of variety, preferably included in the price of the room; little treats in the guest rooms such as cookies or wine and snacks; beautifully appointed bathrooms with separate showers, good water pressure and hot water, and high quality designer toiletries) are expected and their absence is noticed. The extras are not as important as guest rooms, service levels, and staff but can distinguish the top luxury hotels.

For moderate hotels, the guest rooms, staff, and to a lesser degree, location are important. Furthermore, creative consumers indicate that guest rooms can be small but need to be clean, well maintained, and have comfortable furniture, particularly a comfortable bed. Unlike guests 
of the luxury hotels, creative consumers staying at moderate hotels do not expect to be catered to, but they do expect staff to be professional, courteous, helpful, and friendly. This applies to all staff that come into contact with guests. Similar to the experience at luxury hotels, it is expected that staff should be able to solve problems, particularly front desk staff. So, while moderate hotels may not need to have as much staff as the luxury hotels, housekeeping and maintenance are not areas that should be skimped on, as creative consumers notice lack of cleanliness and poor maintenance. Most of the hotels included in this study were centrally located in major cities and the good locations were mentioned in the online reviews. However, the good locations were not enough to overcome room and service issues, as many of the negative reviews mentioned that the only positive thing about the hotel was its location.

Many moderate hotels have executive lounges and floors and the creative consumers experiencing these were more likely to post positive reviews. Good bathrooms were appreciated and luxury not expected but duly noted. Small bathrooms were accepted when they were well appointed, clean, well maintained, with thick and bright towels and quality bath products. Bathrooms, while not as important as the room and staff, can make the difference between a positive review and a negative one. Creative consumers staying at moderate hotels identified irritants that may not affect the overall rating in a review but could be an area of differentiation. Their advice is to serve a good breakfast, either included in the price of the room or at a reasonable price, have a refrigerator and safe in the room, and free Internet access.

A content analysis can be used to quickly analyze consumer-generated content, identify any changes in themes and concepts over time, and then management can use these findings to investigate greater specificity through surveys. For example, if a hotel historically experiences positive comments about the bathroom in the online hotel reviews and these comments stop 
appearing, hotel management can then use surveys to identify how the bathrooms can be improved, with specific options for their guests to consider.

\subsection{Implications for Creative Consumer Research}

With creative consumers creating their own user-generated content in the form of online hotel reviews and hotel star ratings, marketing messages are now less controlled by the marketer. Prior to purchase, consumers are viewing comments and candid photos posted by fellow consumers rather than just being influenced by carefully crafted messages and expensive, posed photographs (RW.ERROR - Unable to find reference:101). The implication is that hotels need to be engaged in managing their creative consumers in order to fully manage their overall marketing communications because potential guests are using eWOM in combination with materials controlled by the hotel. In the category of hotels and TripAdvisor, a study by O'Connor (2008) found that hotels rarely used the right to reply feature on TripAdvisor. In this study, it was observed that a small minority of hotels used this reply feature, so this is still not a widely used feature.

Because the purchase of a service such as a hotel stay is higher in perceived risk than a purchase of a good that can be tried prior to purchase, Murray (1991) identifies word-of-mouth as the most important source of "risk-reducing information", with far more influence on consumers than mass media. Murray further indicates that the type of information consumers seek for a service is not necessarily just objective and technical information but information that is interpretive, subjective, and of an affective nature. This is precisely the type of information that is imparted by creative consumers in the online hotel reviews in this study. While objective and technical information such as descriptions of a room, whether a hotel has a pool, dining 
services, spa, and so on, is easily provided by the hotel website, other information such as whether the bathrooms are spotlessly clean, whether the staff cite rules and policies, and whether a shower has good water pressure, is valuable to consumers through eWOM and gives them greater confidence when making the purchase decision. Creative consumers, particularly in the hotel category, play an enormously important role in providing information that is interpretive, subjective, and of an affective nature to assist their fellow consumers.

In fact, given the specific nature and breadth of information sought by consumers seeking pre-purchase information, it may behoove hotel managers and other service marketers to encourage reviews by creative consumers, consistent with the enable stance described by Berthon et al. (2007). This information-seeking behaviour by those intending to purchase a service suggests consumers may prefer to purchase from an organization with an ample number of reviews than from an organization without any reviews. Thus, a hotel or other service provider may have a competitive advantage if it provides the means for and encourages its customers to become creative consumers, perhaps through such means as providing links on their website to third party online review websites.

\section{$\underline{5.3 \text { Limitations and Areas for Future Research }}$}

This study included online hotel reviews only from TripAdvisor because it was the largest online hotel review site. However, this may have limited the findings. Including reviews about the same hotels from other online hotel review sites may have provided greater insights.

The study included only English hotel reviews, even though TripAdvisor includes reviews in other languages. Including only English hotel reviews may have biased the findings in that they may be applicable only to English-speaking guests. 
This qualitative study, even though it included over 7,000 hotel reviews, included only 17 hotel chains and 51 hotels. Further quantitative studies involving a broad representation of hotels, chain hotels, independent hotels, and budget hotels may provide further insights.

This study, because it was about consumers creating reviews, rather than consumers reading reviews, did not delve into the effect that the reviews had on actual bookings. On TripAdvisor, hotel management could respond to consumer reviews and it was observed that only a few hotels chose to do so. It would be interesting to find out how hotel responses affect consumers' views of these particular hotels.

\subsection{Conclusions}

Businesses can and should harness the power of creative consumers and their online reviews. Potential customers value eWOM to augment the information provided by the marketer, or hotel in this study. With consumers seeking reviews provided by their fellow consumers and relying on these reviews more than reviews by experts or marketer-provided information (Gretzel and Yoo, 2008; Sparks and Browning, 2011), businesses have an enormous opportunity to incorporate these reviews, firstly as a key element of their marketing communications initiatives and, secondly through heeding the advice from creative consumers as part of ongoing market research. Those hotels that can act on the advice from creative consumers are accepting a gift of competitive advantage. 
Figures and Tables

Figure 1: Leximancer Concept Map of Positive Reviews for Luxury Hotel Chains

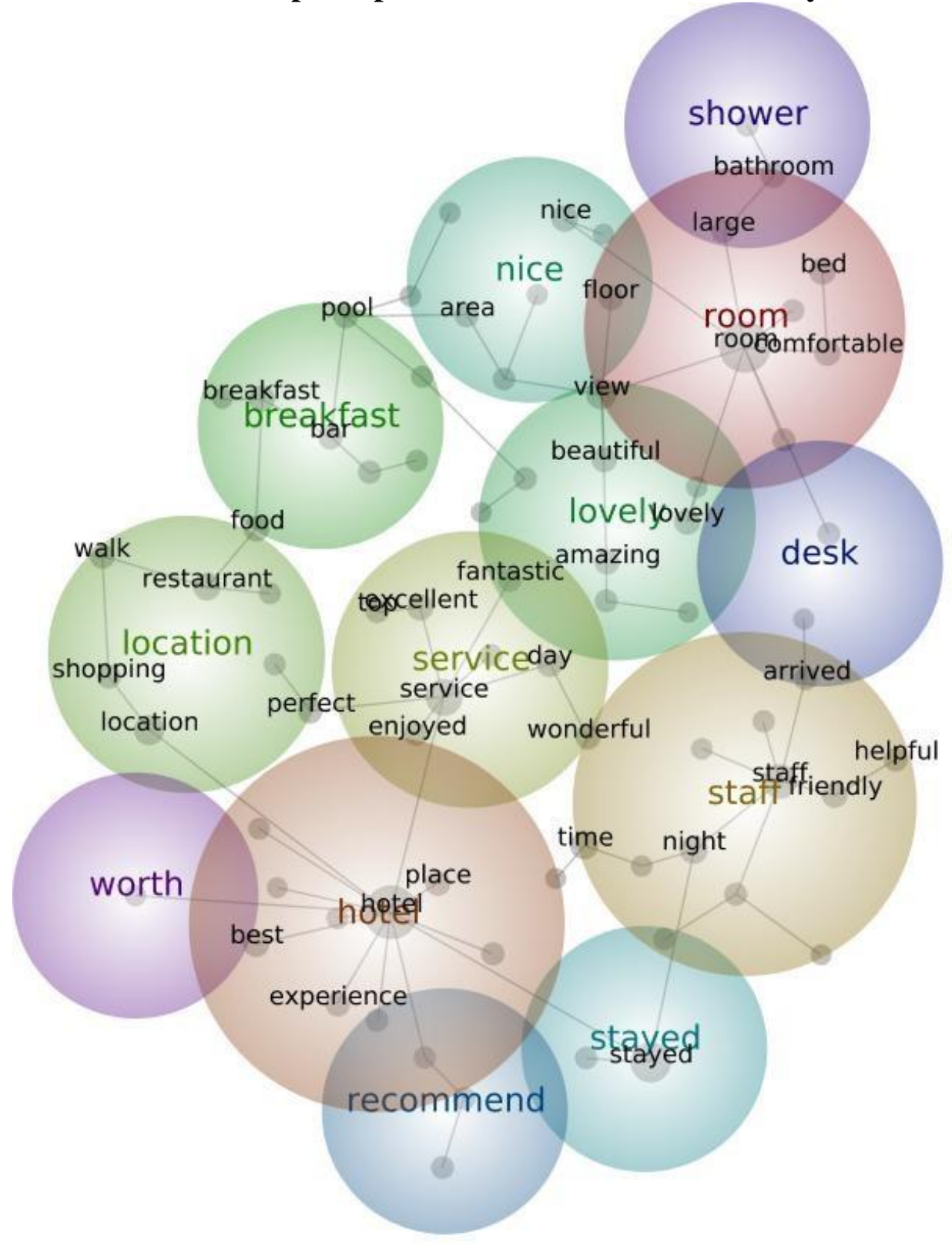


Figure 2: Leximancer Concept Map of Negative Reviews for Luxury Hotel Chains

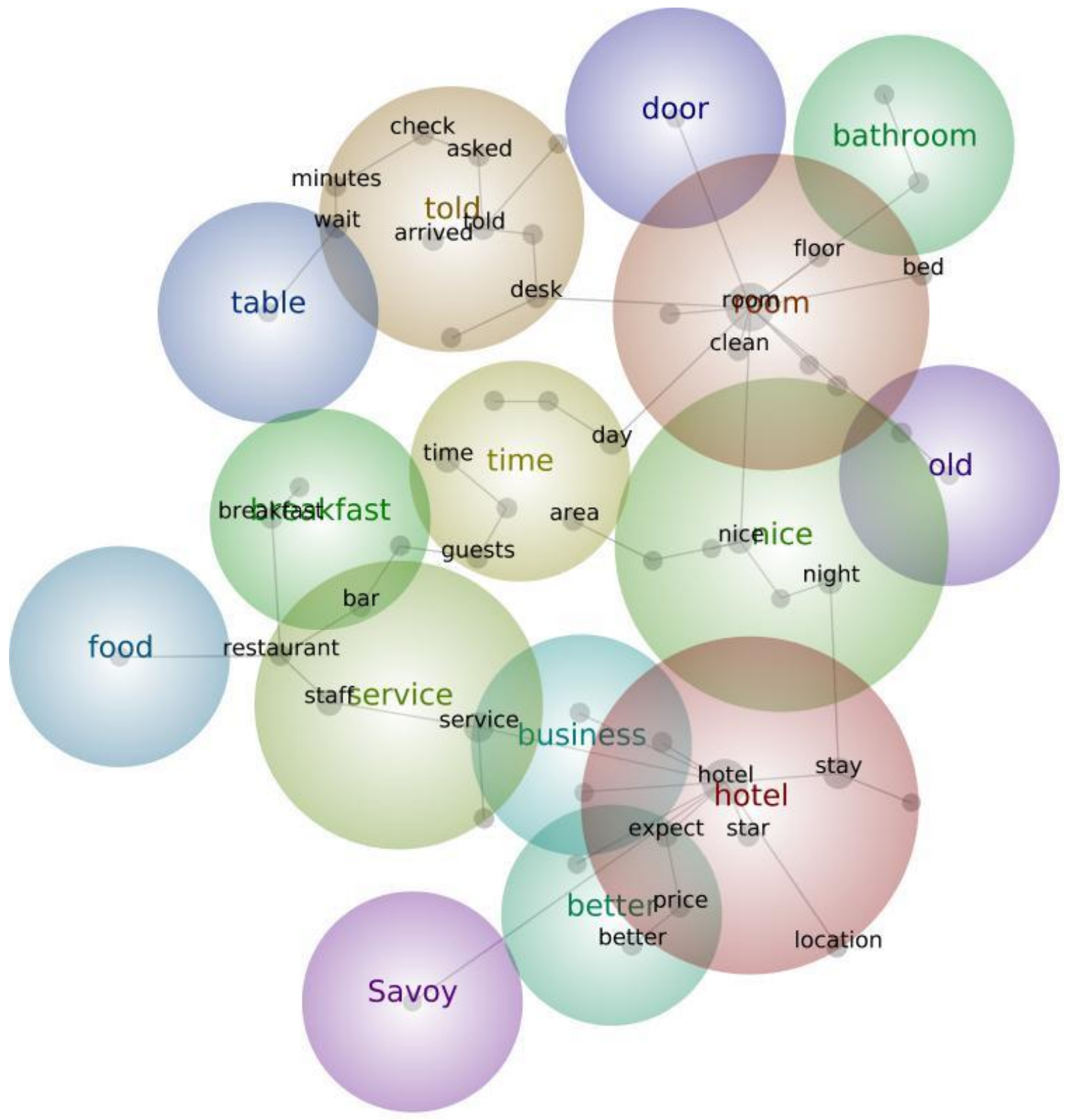


Figure 3: Leximancer Concept Map of Positive Reviews for Moderate Hotel Chains

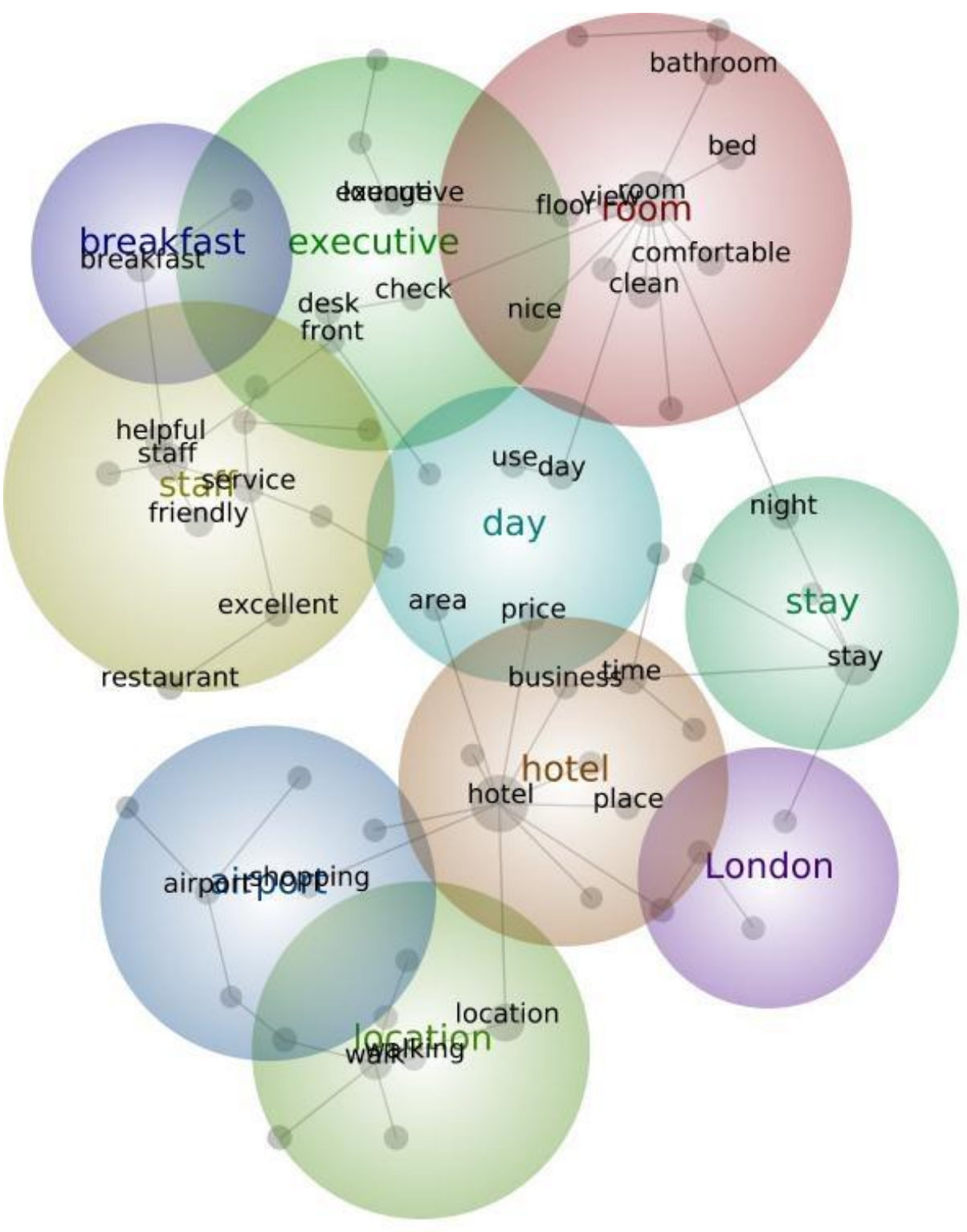


Figure 4: Leximancer Concept Map of Negative Reviews for Moderate Hotel Chains

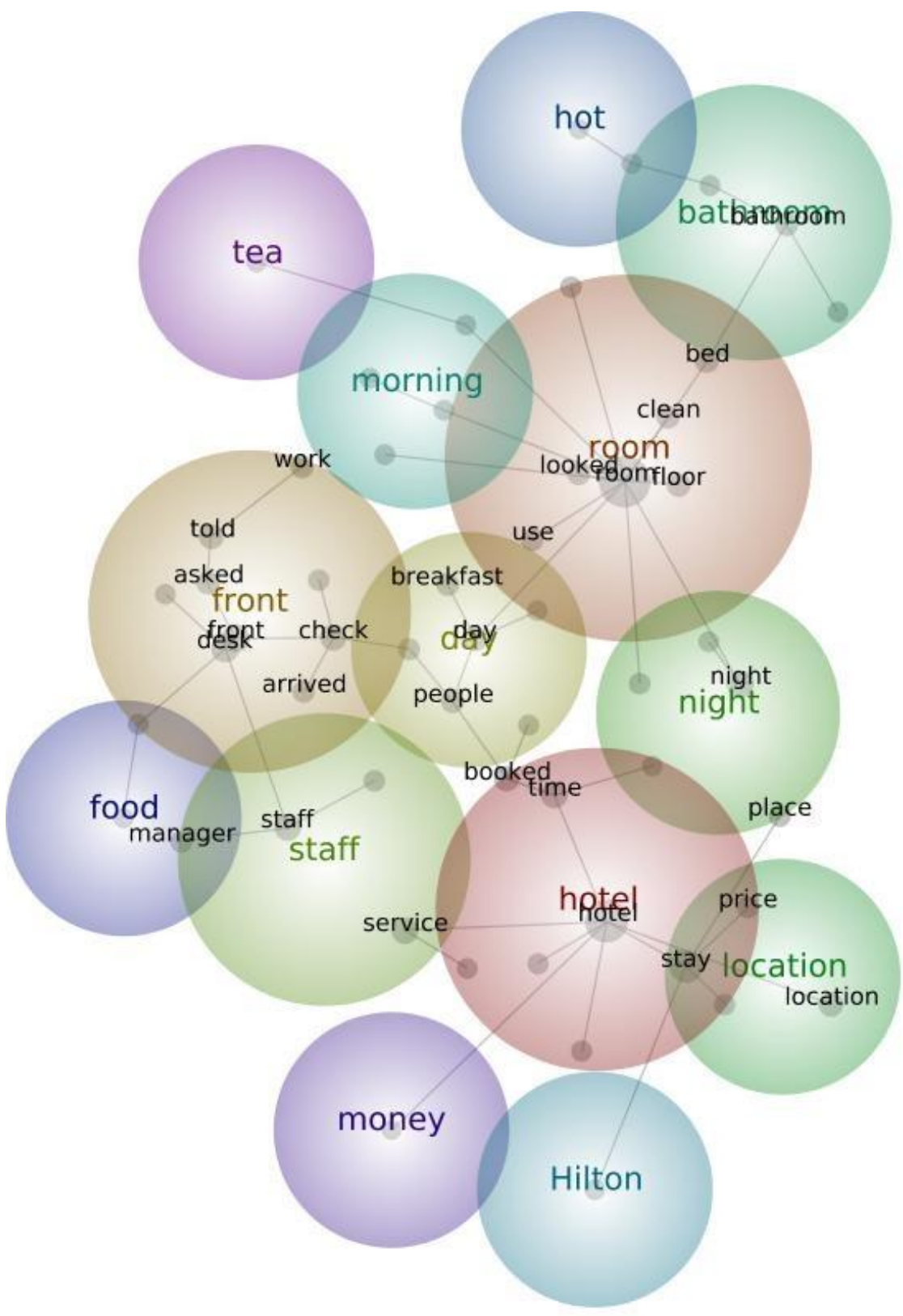


Table 1: Common and Unique Themes among Luxury Hotel Chain Reviews

\begin{tabular}{|c|c|c|}
\hline $\begin{array}{c}\text { Common Themes } \\
\text { Positive and Negative } \\
\text { Reviews }\end{array}$ & $\begin{array}{c}\text { Positive Reviews } \\
\text { Unique Themes }\end{array}$ & $\begin{array}{c}\text { Negative Reviews } \\
\text { Unique Themes }\end{array}$ \\
\hline Room & Staff & Time \\
Hotel & Location & Told \\
Service & Lovely & Better \\
Breakfast & Stayed & Business \\
Nice & Recommend & Bathroom \\
& (Front) Desk & Food \\
& Worth & Table \\
& Shower & Door \\
& & Old \\
& & Savoy \\
\hline
\end{tabular}


Table 2: Common and Unique Themes among Moderate Hotel Chain Reviews

\begin{tabular}{|c|c|c|}
\hline $\begin{array}{c}\text { Common Themes } \\
\text { Positive and Negative } \\
\text { Reviews }\end{array}$ & $\begin{array}{c}\text { Positive Reviews } \\
\text { Unique Themes }\end{array}$ & $\begin{array}{c}\text { Negative Reviews } \\
\text { Unique Themes }\end{array}$ \\
\hline Room & Executive & Front (desk) \\
Hotel & Stay & Night \\
Ltaff & Airport & Bathroom \\
Day & Breakfast & Morning \\
& London & Hot \\
& & Tea \\
& & Food \\
& & Money \\
& & Hilton \\
\hline
\end{tabular}


Appendix 1: List of Hotels Studied

\begin{tabular}{|l|l|}
\hline \multicolumn{1}{|c|}{ Hotel Chain } & \multicolumn{1}{c|}{ Cities Where Hotels Were Studied } \\
\hline Luxury & \\
\hline Four Seasons Hotels and Resorts & New York, London, Hong Kong \\
\hline Mandarin Oriental & New York, London, Hong Kong \\
\hline Peninsula Hotels & New York, Tokyo, Hong Kong \\
\hline Shangri-La Hotels & Vancouver, London, Hong Kong \\
\hline Fairmont Hotels and Resorts & New York, London, Singapore \\
\hline Ritz-Carlton & New York, London, Hong Kong \\
\hline Park Hyatt & Chicago, Paris, Tokyo \\
\hline Hyatt & New York, London, Hong Kong \\
\hline JW Marriott & Chicago, London, Hong Kong \\
\hline Iberostar & $\begin{array}{l}\text { Sardinia (Italy), Playa Paraiso (Mexico), Berkane } \\
\text { (Morocco) }\end{array}$ \\
\hline Relais \& Chateaux & New York, Paris, Canterbury (New Zealand) \\
\hline Jumeirah & London, Dubai, Mallorca (Spain) \\
\hline Moderate & \\
\hline Marriott & New York, London, Hong Kong \\
\hline Best Western & New York, London, Hong Kong \\
\hline Hilton & New York, London, Hong Kong \\
\hline Ramada & New York, London, Hong Kong \\
\hline Holiday Inn & New York, London, Hong Kong \\
\hline
\end{tabular}




\section{References}

BARSKY, J. and NASH, L., , Hotels acknowledge growing impact of user reviews, but unsure how to respond [Homepage of Market Metrix], [Online]. Available:

http://www.marketmetrix.com/en/default.aspx?s=research\&p=hotelsacknowledgegrowin gimpactofuserreviews [November 17, 2012].

BERTHON, P.R., PITT, L.F., MCCARTHY, I. and KATES, S.M., 2007. When customers get clever: Managerial approaches to dealing with creative consumers. Business Horizons, 50(1), pp. 39-47.

BURROUGHS, J.E. and MICK, D.G., 2004. Exploring antecedents and consequences of consumer creativity in a problem-solving context. Journal of Consumer Research, 31(2), pp. 402-411.

CAMPBELL, C., PITT, L.F., PARENT, M. and BERTHON, P.R., 2011. Understanding consumer conversations around ads in a Web 2.0 world. Journal of Advertising, 40(1), pp. 87-102.

CHAN, E.S.W. and WONG, S.C.K., 2006. Hotel selection: when price is not the issue. Journal of Vacation Marketing, 12(2), pp. 142-159.

CHAVES, M.S., GOMES, R. and PEDRON, C., 2011. Analysing reviews in the Web 2.0: Small and medium hotels in Portugal. Tourism Management, pp. 1286-1287.

CHOI, T.Y. and CHU, R., 2001. Determinants of hotel guests' satisfaction and repeat patronage in the Hong Kong hotel industry. International Journal of Hospitality Management, 20(3), pp. 277-297.

DAUGHERTY, T., EASTIN, M.S. and BRIGHT, L., 2008. Exploring consumer motivations for creating user-generated content. Journal of Interactive Advertising, 8(2), pp. 1-24.

DOLNICAR, S., 2002. Business travellers' hotel expectations and disappointments: A different perspective to hotel attribute importance investigation. Asia Pacific Journal of Tourism Research, 7(1), pp. 29-35.

GRETZEL, U. and YOO, K.H., 2008. Use and impact of online travel reviews. Information and Communication Technologies in Tourism 2008, pp. 35-46.

HENNIG-THURAU, T., GWINNER, K.P., WALSH, G. and GREMLER, D.D., 2004. Electronic word-of-mouth via consumer-opinion platforms: What motivates consumers to articulate themselves on the Internet? Journal of Interactive Marketing, 18(1), pp. 38-52.

KATTIYAPORNPONG, U. and NEL, D., 2012. Regional branding: perspectives of tourists in Australia, ANZMAC 2009: Sustainable Management and Marketing Conference 2012, Monash University, pp. 1-8. 
KIETZMANN, J.H., HERMKENS, K., MCCARTHY, I.P., and SILVESTRE, B.S., 2011. Social Media? Get Serious! Understanding the Functional Building Blocks of Social Media.

Business Horizons, 54, pp. 241-251.

KOZINETS, R.V., HEMETSBERGER, A. and SCHAU, H.J., 2008. The Wisdom of Consumer Crowds Collective Innovation in the Age of Networked Marketing. Journal of Macromarketing, 28(4), pp. 339-354.

LAU, K.N., LEE, K.H. and HO, Y., 2005. Text mining for the hotel industry. Cornell Hotel and Restaurant Administration Quarterly, 46(3), pp. 344-362.

LEXIMANCER, 2011-last update, Leximancer Manual Version 4 [Homepage of Leximancer], [Online]. Available: https://www.leximancer.com/lp/4.00.17L115521/m/doc/LeximancerManual.pdf [October, 2012].

LITVIN, S.W., 2000. Revisiting the heavy-user segment for vacation travel marketing. Journal of Vacation Marketing, 6(4), pp. 346-356.

MAY, K., July 12, 2012-last update, Naked truth about online hotel reviews [Homepage of tnooz], [Online]. Available: http://www.tnooz.com/2012/07/12/news/naked-truth-aboutonline-hotel-reviews-infographic/ [November 17, 2012].

MCCARTHY, I.P., LAWRENCE, T.B., WIXTED, B., and GORDON, B., 2010. A Multidimensional conceptualization of environmental velocity. Academy of Management Review, 35(4), pp. 604-626.

MIAO, L., KUO, P.J. and LEE, B.Y., 2011. Consumers' responses to ambivalent online hotel reviews: The role of perceived source credibility and pre-decisional disposition. International Journal of Hospitality Management, 30(1), pp. 178-183.

MORELOCK, J., , Top 10 Luxury Hotel Chains [Homepage of USA Today], [Online]. Available: http://traveltips.usatoday.com/top-10-luxury-hotel-chains-101730.html [October, 2012].

MUDAMBI, S.M. and SCHUFF, D., 2010. What makes a helpful online review? A study of customer reviews on Amazon.com. MIS Quarterly, 34(1), pp. 185-200.

\section{References}

Daugherty, T., Eastin, M. S., \& Bright, L. (2008). Exploring consumer motivations for creating user-generated content. Journal of Interactive Advertising, 8(2), 1-24. 
Dolnicar, S. (2002). Business travellers' hotel expectations and disappointments: A different perspective to hotel attribute importance investigation. Asia Pacific Journal of Tourism Research, 7(1), 29-35.

Hirschman, E. C. (1980). Innovativeness, novelty seeking, and consumer creativity. Journal of Consumer Research, , 283-295.

Keen, A. (2008). The cult of the amateur: How blogs, MySpace, YouTube, and the rest of today's user-generated media are destroying our economy, our culture, and our values Crown Business.

May, K. (2012). Naked truth about online hotel reviews. Retrieved from http://www.tnooz.com/2012/07/12/news/naked-truth-about-online-hotel-reviewsinfographic/

PITT, L., CAMPBELL, C., BERTHON, P., NEL, D. and LORIA, K., 2008. Measuring tourism website communication out of Central America. Imprint, 2008, pp. 01-01.

ROONEY, D., 2005. Knowledge, economy, technology and society: The politics of discourse. Telematics and Informatics, 22(4), pp. 405-422.

SAMSEL, J., June 12, 2012, 2012-last update, The World's 10 Best Hotel Chains [Homepage of Heardable, Inc.], [Online]. Available: http://heardablereports.myshopify.com/products/the-worlds-10-best-hotel-chains [October, 2012].

SPARKS, B.A. and BROWNING, V., 2011. The impact of online reviews on hotel booking intentions and perception of trust. Tourism Management, 32(6), pp. 1310-1323.

TRIPADVISOR, I., July 2012, 2012-last update, About TripAdvisor [Homepage of TripAdvisor, Inc.], [Online]. Available: http://www.tripadvisor.com/pages/about_us.html [December 2012, 2012].

VAN DIJCK, J., 2009. Users like you? Theorizing agency in user-generated content. Media, culture, and society, 31(1), pp. 41. 
VERMEULEN, I.E. and SEEGERS, D., 2009. Tried and tested: The impact of online hotel reviews on consumer consideration. Tourism Management, 30(1), pp. 123-127.

VICKERY, G. and WUNSCH-VINCENT, S., 2007. Participative web and user-created content: Web 2.0 wikis and social networking. Organization for Economic Cooperation and Development (OECD).

WHITEHEAD, L., 2011. Identifying future research opportunities in online consumer reviews: the case study of 'TripAdvisor'. International Journal of Technology Marketing, 6(4), pp. 341-354. 